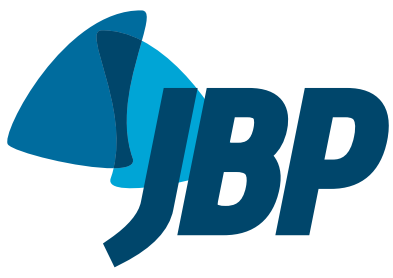

\title{
What does the increasing prevalence of obesity mean for the management of asthma and airways disease?
}

\author{
Jodie L Simpson ${ }^{1}$ (D), Hayley A Scott ${ }^{1}$ (D)
}

There is a global epidemic of obesity and, coinciding with this, a high prevalence of obesity coexisting with asthma. Research suggests that adults with asthma and obesity have asthma that is more severe, including poorer control, reduced lung function, and more frequent exacerbations, than do those with asthma who are not obese. (1) They also have a diminished response to asthma pharmacotherapy, including $\beta_{2}$ agonists, inhaled corticosteroids, and montelukast. ${ }^{(2)}$ The reduced efficacy of maintenance and reliever medications likely plays an important role in poorer asthma outcomes. However, we still do not properly understand the impact that obesity has on asthma outcomes, the mechanisms responsible, or the ideal management approach, which represents a major problem.

In a study published in this issue of the JBP, Souza et al. ${ }^{(3)}$ examined the prevalence of respiratory symptoms and asthma according to body mass index, as well as evaluating the factors associated with asthma in more than 1,000 adults 40 years of age or older. Their study was a cross-sectional subanalysis of the Respira Floripa study, in which the study population was derived from a metropolitan area in Brazil. Participants self-reported respiratory symptoms and underwent pulmonary function tests. The authors demonstrated that a diagnosis of asthma is more common in obese individuals, physician-diagnosed asthma being three times more common in individuals who are obese than in those of normal weight. This is in line with the findings of a 2007 meta-analysis showing that obesity precedes the development of asthma, nearly doubling the odds of incident asthma. In their study, Souza et al.(3) also showed that the prevalence of respiratory symptoms, particularly dyspnea and wheezing, are highest in obese individuals, irrespective of smoking status. Notably, the authors found that, among nonsmokers, chronic expectoration and chronic bronchitis-like symptoms were most common in those who were obese, whereas the prevalence of chronic expectoration did not differ by weight category among current and former smokers. That finding suggests that smoking masks the obesity-induced effects of mucous production. Among the nonsmokers, rhinitis was common and its prevalence was higher in those who were obese, whereas it was similar among the current and former smokers, independent of body mass index. This was an important real-world study that adds to our understanding of the impact of obesity in adults with asthma.

Although the mechanisms responsible for the association between obesity and asthma are not clear, it is likely due to a combination of inflammatory and mechanical influences. The rise in obesity is thought to be the result of changing lifestyles, a poor diet and physical inactivity being the key drivers. Such changes lead to excess adipose tissue, together with alterations in the microbiota and immune system, including increases in IL-6 and TNF-a. ${ }^{(4)}$ Obesity is characterized by an increase in neutrophils, in the adipose tissue and in the circulation. ${ }^{(5,6)}$ Our group, ${ }^{(4)}$ as well as others, ${ }^{(7-9)}$ observed an increase in neutrophils in the sputum of obese adults with asthma, suggesting that the systemic inflammatory effects of obesity extend to the airways of susceptible individuals with asthma. In relation to the mechanical effects, fat tissue in the chest wall reduces chest wall movement and chest cavity volume, whereas abdominal fat tissue limits lung inflation by reducing the ability of the diaphragm to shift downwards. ${ }^{(10)}$ That may contribute to reduced lung function and the sensation of dyspnea in obese adults with asthma.

The effective management of asthma in obese individuals requires an individualized, multidisciplinary approach, including the assessment and treatment of comorbid disease. Souza et al. (3) found that wheezing and dyspnea were both more common in obese individuals. In another study conducted by our group, ${ }^{(11)}$ we demonstrated that a $5-10 \%$ weight loss is effective for improving asthma control (including symptoms of wheezing and dyspnea), as well as lung function and asthma-related quality of life, in overweight and obese adults with asthma. Taken together, these findings suggest that, although obesity worsens wheezing and dyspnea, a modest weight loss can effectively reduce those symptoms. Souza et al.(3) also found that the prevalence of heart disease and diabetes is higher in obese individuals, who also have the highest incidence of asthma. This is indicative of the increasing burden of chronic disease in the population over 40 years of age and, because heart disease and diabetes are both also associated with increased systemic inflammation, underscores the need to assess and manage systemic and airway inflammation in individuals with asthma. The greater neck circumference in obese individuals also suggests that assessment and management of sleep apnea are likely to be critical and may improve quality of life in those with asthma. Although there have been some studies suggesting possible treatment pathways, much more research is needed. Due to the paucity of research in the area, guidelines for the management of obesity-associated asthma do not exist. Further studies such as this are urgently needed so that management guidelines can be developed.

In conclusion, the Souza et al. study ${ }^{(3)}$ provides important new data regarding the association between obesity and a diagnosis of asthma, as well as the clinical consequences 
of obesity in individuals with established disease. The findings corroborate those of previous studies in this area and will facilitate the development of clinical guidelines for the management of obesity-associated asthma, which currently do not exist. Further research is needed in order to determine the ideal treatment pathway for managing symptoms and improving patient outcomes in obesity-associated asthma.

\section{REFERENCES}

1. Scott HA, Wood LG, Gibson PG. Role of Obesity in Asthma: Mechanisms and Management Strategies. Curr Allergy Asthma Rep. 2017;17(8):53. https://doi.org/10.1007/s11882-017-0719-9

2. Camargo CA Jr, Boulet LP, Sutherland ER, Busse WW, Yancey SW Emmett $A H$, et al. Body mass index and response to asthma therapy: fluticasone propionate/salmeterol versus montelukast. J Asthma. 2010;47(1):76-82. https://doi.org/10.3109/02770900903338494

3. Souza ECC, Pizzichini MMM, Dias M, Cunha MJ, Matte DL, Karloh M, Maurici R, Pizzichini E. Body mass index, asthma, and respiratory symptoms: a population-based study. J Bras Pneumol. 2020;46(1):e20190006. https://doi.org/10.1590/1806-3713/ e20190006

4. Scott HA, Gibson PG, Garg ML, Wood LG. Airway inflammation is augmented by obesity and fatty acids in asthma. Eur Respir J. 2011;38(3):594-602. https://doi.org/10.1183/09031936.00139810

5. Nijhuis J, Rensen SS, Slaats Y, van Dielen FM, Buurman WA, Greve JW. Neutrophil activation in morbid obesity, chronic activation of acute inflammation. Obesity (Silver Spring). 2009;17(11):2014-2018. https://doi.org/10.1038/oby.2009.113

6. Shah TJ, Leik CE, Walsh SW. Neutrophil infiltration and systemic vascular inflammation in obese women. Reprod Sci. 2010;17(2):116 124. https://doi.org/10.1177/1933719109348252
7. Telenga ED, Tideman SW, Kerstiens HA, Ten Hacken NH, Timens W Postma DS, et al. Obesity in asthma: more neutrophilic inflammation as a possible explanation for a reduced treatment response. Allergy. 2012;67(8):1060-1068. $\quad$ https://doi.org/10.1111/j.13989995.2012.02855.x

8. Marijsse GS, Seys SF, Schelpe AS, Dilissen E, Goeminne P, Dupont $L J$, et al. Obese individuals with asthma preferentially have a high IL-5/IL-17A/IL-25 sputum inflammatory pattern. Am J Respir Crit Care Med. 2014;189(10):1284-1285. https://doi.org/10.1164/ rccm.201311-2011LE

9. Chen JH, Qin L, Shi YY, Feng JT, Zheng YL, Wan YF, et al. IL-17 protein levels in both induced sputum and plasma are increased in stable but not acute asthma individuals with obesity. Respir Med. 2016;121:48-58. https://doi.org/10.1016/j.rmed.2016.10.018

10. Salome CM, King GG, Berend N. Physiology of obesity and effects on lung function. J Appl Physiol (1985). 2010;108(1):206-211. https:// doi.org/10.1152/japplphysiol.00694.2009

11. Scott HA, Gibson PG, Garg ML, Pretto JJ, Morgan PJ, Callister R, et al. Dietary restriction and exercise improve airway inflammation and clinical outcomes in overweight and obese asthma: a randomized trial. Clin Exp Allergy. 2013;43(1):36-49. https://doi.org/10.1111/ cea.12004 